\title{
GESTÃO PARTICIPATIVA COMO PROPOSTA PARA APROXIMAR OS VISITANTES DO CUIDADO DAS ÁREAS NATURAIS: O MANEJO DE UMA TRILHA DE CICLISMO DE MONTANHA
}

\author{
Carolina Teixeira Bartoletti \\ Universidade de São Paulo \\ Piracicaba/São Paulo/Brasil \\ E-mail: carolina.bartoletti@usp.br \\ ORCID: https://orcid.org/0000-0002-2531-5557
}

Teresa Cristina Magro Lindenkamp

Universidade de São Paulo

Piracicaba/São Paulo/Brasil

E-mail: teresa.magro@usp.br

ORCID: https://orcid.org/0000-0002-8999-3509

Recebido em 30/09/2020 aprovado em 15/03/2021

DOI: http://dx.doi.org/10.5380/guaju.v7i1.76922

\section{Resumo}

Nos últimos anos foi registrado um aumento da visitação de áreas naturais protegidas para a prática de atividades esportivas e recreativas de aventura. $\mathrm{Na}$ contrapartida do aumento da visitação, estas áreas continuam defasadas em recursos humanos e financeiros para realizar a conservação do meio ambiente. Existem já há muitos anos inciativas de gestão participativa, seja na forma de voluntariado ou formação de conselhos gestores, para incluir a sociedade no cuidado das áreas protegidas. Na Estação Experimental de Tupi, no município de Piracicaba/SP, existe a visitação de ciclistas de montanha, que pelo fato de o ciclismo não ter sido uma atividade prevista no Plano de Manejo, utilizam trilhas inicialmente pensadas para pedestres. Foi proposto para estes visitantes o planejamento e manejo participativos de uma trilha para ciclismo, inspirados na experiência de Newsome et al. (2016) no sudoeste australiano. O objetivo foi aumentar a comunicação entre os ciclistas e a gestão da Estação Experimental de Tupi, visando a ampliar a escuta de suas demandas enquanto visitantes e incluí-los no cuidado da área. O processo de gestão participativa iniciou com a aplicação de questionários estruturados presenciais, teve sete encontros para o planejamento 
e manejo da trilha e culminou na abertura da Trilha do Limoeiro, embora a participação dos ciclistas, neste caso, tenha sido esporádica.

Palavras-chave: gestão participativa, uso público, áreas protegidas, Estação Experimental de Tupi, ciclismo de montanha.

\title{
Participatory Management as a Proposal to Bring Visitors Closer to the Care for Natural Areas: A Mountain Bike Trail Management
}

\begin{abstract}
There has been an enhancement in the use of protected areas for adventure sports. On the counterpoint of this enhancement, most protected areas still lack human and financial resources for environmental conservation. Participatory management initiatives such as volunteer work and the formation of management councils are well known strategies to include society in the conservation of nature. At Estação Experimental de Tupi, a protected area located in Piracicaba/SP, mountain bikers use trails originally designed for pedestrians as mountain bike trails was not initially included as predicted form of use. On this research, it was proposed for these bikers the participatory management of a trail designed specifically for mountain bike, inspired by an experience in Australia reported by Newsome et al. (2016). The goal was to bring closer bikers and the management of Estação Experimental de Tupi, by listening to their demands as visitors and including them in the care for the area. The participatory management process initiated with surveys and was composed of seven encounters to plan and manage the trail. It culminated in the opening of Trilha do Limoeiro trail, yet only a handful of bikers participated.

Keywords: Participatory management, Public use, Protected areas, Estação Experimental de Tupi, Mountain bike.
\end{abstract}




\section{Introdução}

Este artigo deriva de uma pesquisa que, por sua vez, se originou da necessidade de melhor compreender um dos tipos de uso público que acontece na Estação Experimental de Tupi, em Piracicaba/SP - o uso feito por ciclistas de montanha - e do desejo de estimular um maior envolvimento civil no cuidado e manutenção das áreas protegidas, uma vez que os gestores destas frequentemente se deparam com defasagens em recursos humanos e financeiros para cumprir os objetivos de conservação e uso público de suas áreas. $\mathrm{Na}$ Estação Experimental de Tupi, por exemplo, durante a condução desta pesquisa (2017 2020), o corpo de trabalhadores contou com treze funcionários fixos do Instituto Florestal, órgão gestor da área, e dois funcionários terceirizados pela Prefeitura de Piracicaba, também gestora da área, para as funções de vigilante e auxiliar do Centro de Visitantes.

Dos treze funcionários vinculados ao Instituto Florestal, apenas três eram funcionários de campo, intitulados auxiliares de serviço e voltados à manutenção dos 198 hectares da Estação, além de se dividirem na tarefa de motoristas dos carros oficiais da unidade. Durante a condução deste trabalho, um dos auxiliares de serviço se aposentou, e nenhum substituto foi contratado.

No que diz respeito ao uso das áreas protegidas para lazer, nos últimos anos foi registrado um aumento do uso para a prática de atividades esportivas e recreativas de aventura (HARDIMAN; BURGIN, 2011). A Outdoor Foundation (2011), nos Estados Unidos, registrou entre 2009 e 2010 um aumento na participação em esportes de aventura que se revelou tanto no aumento percentual de participação como no surgimento de novas modalidades esportivas. Por exemplo, houve nos Estados Unidos um aumento de $35 \%$ na prática de caiaque em águas doces, $21 \%$ na prática de caiaque no mar e $20 \%$ na prática de escalada ao ar livre neste período.

Outra crescente prática de atividade de aventura em áreas protegidas é a mountain bike, ou ciclismo de montanha (WOLF et al, 2014). Haddad et al (2015) e Newsome et al (2012) apontam, inclusive, para o aumento específico do uso de reservas e parques naturais próximos a centros urbanos para atividades como a corrida, a caminhada e o ciclismo de montanha.

Este é o caso, por exemplo, da Estação Experimental de Tupi, uma área natural protegida cogerida pelo Instituto Florestal (SP) e pela Prefeitura de Piracicaba, onde existe uma crescente demanda pela prática de atividades esportivas e recreativas, dentre as quais 
o ciclismo de montanha, a corrida de orientação, caminhada e corrida em trilha (INSTITUTO FLORESTAL, 2016).

É interessante notar, contudo, que diferentemente do modelo estadunidense de parques, de modo geral as áreas protegidas brasileiras tiveram um foco maior na conservação do meio ambiente, com um modelo de gestão mais voltado para o controle das atividades realizadas no interior das unidades de conservação (UCs). O desenvolvimento de atividades de lazer e recreação, e o fomento ao turismo nessas áreas só começou a se desenvolver nos anos 1980 (MATHEUS; RAIMUNDO, 2016).

Mas apesar do desenvolvimento relativamente recente das atividades de uso público, dados atuais indicam um aumento da visitação e da prática de atividades esportivas de aventura em diversas UCs brasileiras. Por exemplo, no Parque Nacional de Jericoacoara (CE), dados revelam um aumento progressivo da visitação anual de 100.000 visitantes em 2013 para 800.000 em 2017, sendo os principais atrativos deste parque as praias, lagoas, dunas e prática de kitesurf e windsurf (ICMBio, 2017).

Já no Parque Nacional do Itatiaia (MG/SP/RJ), onde a caminhada em trilha e a escalada são atividades populares, a visitação anual subiu dos 96.000 visitantes em 2012 para 139.000 em 2017 (ICMBio, 2020).

Embora pautada em uma lógica antropocêntrica que atribui à natureza funções utilitárias e, portanto, a valoriza pelo que ela pode oferecer à humanidade e não necessariamente por um valor intrínseco, como no caso dos ecologistas profundos 1 (HEYWOOD, 2010), essa visão do uso público nas unidades de conservação permite a possibilidade de buscar parceiros para a conservação ambiental: as pessoas cujo lazer é ao ar livre na natureza.

Isso se torna particularmente importante à luz da atual conjuntura de cortes de investimento na área de meio ambiente. Por exemplo, Newsome et al (2016) relatam uma experiência de construção de parceria entre as agências governamentais responsáveis pela gestão de áreas protegidas australianas e grupos de ciclistas que utilizavam estas áreas para recreação. Em decorrência da gestão participativa das trilhas para ciclismo nestas áreas, os autores relatam uma diminuição no impacto ambiental da abertura informal de trilhas, e um aumento na satisfação dos ciclistas com a visitação dos parques e reservas.

\footnotetext{
10 ecologismo é uma ideologia política que surge em reação ao forte processo de industrialização no mundo e que, diferentemente de outras, não coloca o homem como centro do universo. Nesta visão, há os ecologistas superficiais, que ainda se atêm a uma visão mais utilitária da natureza, e os chamados ecologistas profundos, que rejeitam veementemente a ideia de que a espécie humana seja superior às demais ou à própria natureza (HEYWOOD, 2010).
} 
A relação do ciclismo de montanha com a conservação das áreas naturais é similar à de outras atividades de aventura e de outros tipos de uso público: o ciclista enquanto visitante das UCs, seja em momentos de lazer, treinamento ou competição, pode tanto ser um aliado quanto comprometer a conservação da natureza.

Isso significa que, dependendo do comportamento do visitante, do ecossistema da área natural e do manejo da visitação desta área, a prática do ciclismo de montanha pode ou não causar a abertura de trilhas secundárias, a dispersão de sementes de espécies exóticas, erosão, conflitos de uso com caminhantes e outros impactos socioambientais (PICKERING et al, 2010).

No caso da Estação Experimental de Tupi, foi realizada uma pesquisa composta pela aplicação de questionários estruturados para os visitantes ciclistas e não ciclistas, buscando identificar relatos de conflitos de uso entre os mesmos, conforme Rossi et al. (2013), e por uma experiência de gestão participativa de uma trilha para ciclismo de montanha.

Os resultados dos questionários foram mais profundamente explorados em um artigo prévio (BARTOLETTI; MAGRO-LINDENKAMP, 2020), e neste será descrita a proposta de gestão participativa, a qual teve por objetivo melhorar a qualidade da visitação na Estação, a partir de um lugar de escuta das demandas dos ciclistas, e possibilitar um aumento da participação pública, principalmente dos grupos interessados no uso recreativo da área, em seu cuidado e manutenção.

\section{Metodologia}

A pesquisa foi estruturada metodologicamente para que, a partir de entrevistas presenciais, fosse iniciado o processo de gestão participativa da trilha, o qual foi constituído de sete encontros mensais ao longo do ano de 2018, sendo cinco para o planejamento participativo e dois para o manejo da trilha em si, culminando na abertura oficial da trilha no Dia Mundial sem Carro, 22 de setembro de 2018. Cabe ressaltar que a proposta de gestão participativa foi inspirada na experiência de Newsome et al (2016) na construção de uma trilha para ciclismo no sudoeste australiano.

O tipo de amostra utilizada nas entrevistas foi a"não probabilística por conveniência" (ou acidental), em que o indivíduo pesquisado é selecionado por estar disponível no local e no momento em que a pesquisa está sendo realizada (MATTAR, 2007). Já o encerramento desta etapa da coleta de dados e, por conseguinte, da amostra de sujeitos entrevistados, 
ao final de 2017 se deu por saturação teórica, ou seja, quando as entrevistas não mais apresentaram elementos novos ou relevantes que pudessem contribuir para a elaboração da etapa seguinte da pesquisa - o planejamento participativo da trilha - ou propiciar um melhor entendimento das questões relacionadas ao uso público dos ciclistas na E.E. Tupi (RHIRY-CHERQUES, 2016).

A abordagem dos sujeitos ocorria próxima ao estacionamento e ao Centro de Visitantes da Estação, por serem estes locais que concentravam os visitantes, inclusive os ciclistas, ainda não engajados na sua atividade recreativa e mais relaxados. Uma vez que abordar os pedestres em trânsito era mais fácil que abordar os ciclistas já montados, foi dada também preferência aos pontos de estacionamento e centro de visitantes pelo fato de os ciclistas ou ainda não estarem pedalando ou fazerem uma pausa para encher as garrafinhas de água nos bebedouros.

Para a realização da pesquisa empírica, utilizou-se a pesquisa-ação, um método de pesquisa social que é concebido e realizado em estreita associação com uma ação ou resolução de problema coletivo - no caso, o planejamento e manejo da trilha - onde pesquisadores e participantes estão envolvidos de modo cooperativo ou participativo (THIOLLENT, 2018). Os questionários aplicados foram parte integrante desta metodologia, uma etapa preliminar de contato com os visitantes da E.E. Tupi.

Anteriormente ao início da coleta de dados em campo, houve um ano de pesquisa bibliográfica e documental para o embasamento teórico do trabalho. A pesquisa bibliográfica foi realizada em bases de dados através do Portal de Busca Integrado da Universidade de São Paulo, em que foram selecionados artigos, livros, teses e dissertações relacionados aos temas do uso público de ciclistas em UCs, e a propostas de gestão participativa e voluntariado em áreas protegidas.

A pesquisa documental referiu-se, por sua vez, à procura de leis, diretrizes e portarias normativas sobre o ciclismo em unidades de conservação. Materiais de referência dos órgãos gestores de UCs no Brasil e, particularmente, do Instituto Florestal do Estado de São Paulo, que faz a cogestão da Estação Experimental de Tupi, foram consultados.

\section{1 Área de estudo}

A Estação Experimental de Tupi faz parte de uma categoria de áreas naturais protegidas, as estações experimentais, com foco na realização de pesquisas e atividades 
científicas (SÃO PAULO, 2017). Contudo, a E.E. Tupi, por ter tido outros tipos de uso e denominações ao longo de sua história, dentre elas Horto de Tupi, ficou conhecida pela população como uma área que oferta também lazer, além de atividades de educação ambiental.

A Estação se localiza no bairro de Tupi, tendo seu acesso principal pela rodovia Luiz de Queiroz (SP 304), que interliga os sistemas Anhanguera (SP 330) e Bandeirantes (SP 348) à cidade de Piracicaba/SP (SÃO PAULO, 2017). Contudo, sabe-se também que há outros acessos à Estação que interligam estradas rurais à mesma, e que são muitas vezes utilizados principalmente pelos ciclistas que vão pedalando, e não de carro, para a Estação.

No aspecto biofísico, a Estação tem uma área de 198 hectares, bioma de Mata Atlântica com floresta estacional semidecidual e áreas reflorestadas com pináceas e eucalipto principalmente em decorrência de pesquisas realizadas em outras épocas. O relevo é de morrotes alongados e espigões, com altitudes entre 505 e 570 metros (SÃO PAULO, 2017). Como não há declividades tão acentuadas que justifiquem trechos da modalidade downhill do ciclismo de montanha, foi verificado que o perfil do ciclista da Estação Experimental de Tupi é o da modalidade cross-country, que se motiva mais por longos caminhos a percorrer, em trilhas largas ou estradas de terra, que propriamente em superar obstáculos ou descidas íngremes, como no downhill.

\section{Resultados}

No Brasil, algumas leis e normativas orientam o manejo de trilhas para ciclismo e a construção de parcerias para sua abertura e manutenção. No estado do Rio de Janeiro, por exemplo, em 2019 foi sancionada e publicada a Lei 8.308/2019 para a criação do Programa de Incentivo ao Ciclismo de Montanha nos parques estaduais e outras áreas públicas do estado (ALERJ, 2019). Segundo a lei, a iniciativa privada pode patrocinar a criação de trilhas e circuitos para o ciclismo de montanha mediante a celebração de termos jurídicos com o poder público, respeitando os planos de manejo das áreas protegidas (ALERJ, 2019).

Já no caso da Estação Experimental de Tupi, a experiência de parceria que se firmou entre os visitantes e a gestão da unidade para a gestão participativa da trilha de ciclismo foi baseada em uma proposta de trabalho voluntário, não de adoção ou patrocínio da trilha.

Ademais, o Instituto Florestal, órgão gestor da Estação, que conta com a cogestão da Prefeitura de Piracicaba na área de visitação, não tem, por sua vez, uma diretriz específica 
para o manejo de trilhas de ciclismo, até porque este não era um uso inicialmente previsto no plano de manejo desta unidade (PINHEIRO et al, 1999).

Assim, a experiência aqui relatada parte de uma pesquisa conduzida pelas autoras sobre o uso público de ciclistas na E.E. Tupi, foi composta por sete encontros, sendo cinco de planejamento e dois de manejo da trilha, elaborados e organizados conforme orientação e diálogo com os profissionais do Instituto Florestal e da Prefeitura de Piracicaba presentes, com discentes de Engenharia Florestal da Universidade de São Paulo e com os visitantes envolvidos nas etapas da gestão participativa.

Segue nesta seção de resultados, a descrição resumida destes encontros e de sua posterior avaliação.

\section{Encontro de planejamento I - fevereiro/2018}

Neste primeiro encontro, uma reunião com os potenciais interessados no manejo da trilha, compareceram vinte e dois visitantes, sendo que apenas dois destes $(9,1 \%)$ foram ciclistas que já haviam sido previamente entrevistados em 2017 na Estação Experimental de Tupi. Nenhum visitante não ciclista previamente entrevistado compareceu.

A ausência de tantos visitantes, ciclistas e não ciclistas, que haviam manifestado interesse em voluntariar quando entrevistados pode se explicar por um conflito de data da reunião com compromissos pessoais, mas também pelo fato de muitos indivíduos manifestarem, quando entrevistados, opiniões que consideram ser a esperada pela sociedade ou mesmo pelo entrevistador (AJZEN, 1991; MANNING, 2009).

Assim, é possível que muitos tenham manifestado interesse em voluntariar para não passar uma imagem negativa na entrevista, mas que, de fato, não tinham a intenção de se engajar na gestão participativa das trilhas de ciclismo da E.E. Tupi.

Também Cortella (2020) fala sobre os termos "consciência invertida" e "concordância ilusória" para tratar de casos em que pessoas simulam concordar com algo, mas na realidade não praticam aquilo que entendem como sendo correto, porque entendem também que não é aplicável ao caso delas.

De qualquer forma, a reunião de fevereiro de 2018 contou com a presença de vinte e dois visitantes, além de duas funcionárias da E.E. Tupi responsáveis pela parte de uso público e educação ambiental, dois funcionários da prefeitura de Piracicaba, uma funcionária do SESC Piracicaba e seis pessoas pertencentes à comunidade acadêmica (cinco estudantes de graduação e uma docente). 
Essas trinta e três pessoas foram divididas em seis grupos de trabalho refletindo ao máximo a diversidade de pares (visitantes, funcionários das instituições gestoras, e comunidade acadêmica) em cada grupo, e foram realizados debates nestes pequenos grupos, posteriormente levados ao coletivo na roda de encerramento da reunião.

Os debates foram acerca das prioridades de atrativos para a futura trilha ciclística - colocando em diálogo coletivo uma questão do questionário de entrevistas para ciclistas - e acerca de prioridades estruturais para melhorar a qualidade da visitação na E.E. Tupi colocando em diálogo coletivo questões de ambos os questionários (para visitantes ciclistas e não ciclistas) que indagavam por que os sujeitos não passavam mais tempo na Estação se por falta de lanchonete, de banheiros, de bebedouros ou por outras razões.

\section{Encontro de planejamento II - março/2018}

No encontro de março de 2018, o objetivo foi iniciar o reconhecimento em campo das possíveis futuras trilhas para ciclismo, atualmente carreadores que permeiam áreas de experimentação científica na E.E. Tupi.

Nessa ocasião, compareceram doze pessoas, entre elas, quatro ciclistas, um funcionário da prefeitura de Piracicaba, dois funcionários do Instituto Florestal e cinco pessoas da comunidade acadêmica (quatro estudantes de graduação e uma docente).

Foi percorrido um trajeto de 2,2 km, que foi nomeado coletivamente como Trilha do Limoeiro, pelo fato de haver vários limoeiros no percurso e por este ser o nome já conhecido pelos funcionários de campo da Estação (figura 1). 
Figura 1: Mapa da Trilha do Limoeiro

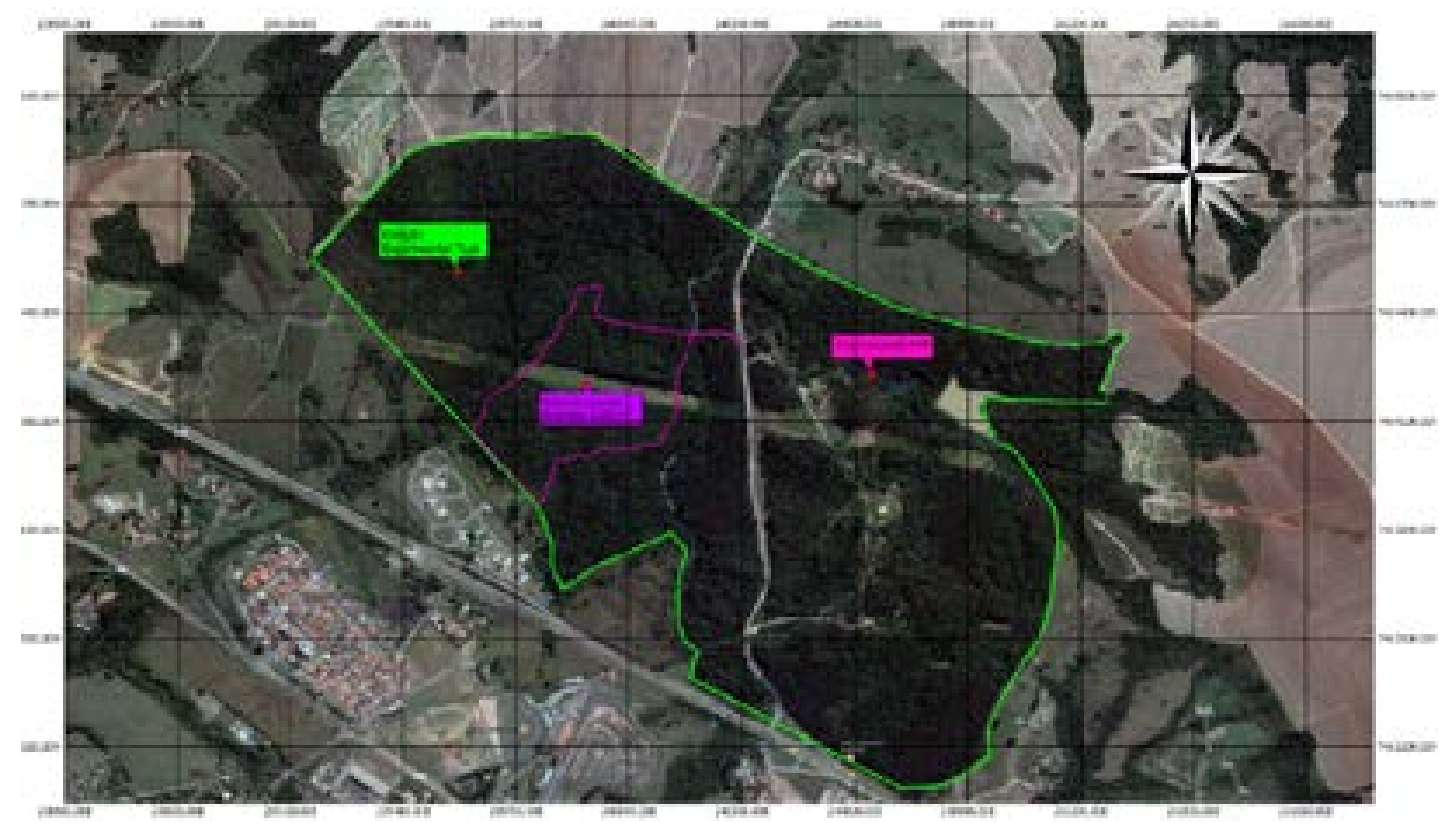

Fonte: Elaborado com o aplicativo Wikiloc.

Também neste encontro, foi decidido coletivamente que a Trilha do Limoeiro seria o objeto de intervenção principal, para que a mesma pudesse ser disponibilizada ao público com as alterações necessárias em 22 de setembro de 2018, um sábado, que é quando se celebra também o Dia Mundial sem carro.

Ficou acordado que outros caminhos poderiam ser também incluídos no manejo de trilhas para ciclismo, sendo que a Trilha do Limoeiro seria o marco inicial da atividade no sistema de trilhas da Estação.

\section{Encontro de planejamento III - abril/2018}

No encontro de abril de 2018, a coleta de dados em campo foi justamente a procura por outras áreas onde se pudesse expandir o percurso da Trilha do Limoeiro e iniciar a criação de um circuito de trilhas para ciclismo de montanha na Estação Experimental de Tupi.

Nessa ocasião, compareceram vinte e uma pessoas, sendo dezesseis ciclistas, uma funcionária do Instituto Florestal, um funcionário da prefeitura de Piracicaba e três pessoas da comunidade acadêmica (três estudantes de graduação). 
Com o mesmo aparato instrumental do encontro anterior, o aplicativo de celular Wikiloc, que demarca caminhos percorridos em mapas, o grupo estudou o lado oposto ao caminhado no encontro de março.

Cabe ressaltar que os carreadores que foram estudados para adaptação a trilhas de ciclismo ficam em uma área da Estação Experimental de Tupi mais distante do Centro de Visitantes, depois da estrada rural de terra que dá acesso à Fazenda Furlan e que divide a Estação ao meio.

Isso porque, apesar das enquetes realizadas com os visitantes terem indicado baixa ocorrência de conflitos de uso entre ciclistas e pedestres, funcionários da Estação recebem reclamações sobre excesso de velocidade dos ciclistas e relatam um aumento da frequência da atividade que pode futuramente intensificar esse tipo de conflito, atualmente pouco relatado.

Assim, a proposta foi adaptar os carreadores a um uso mais específico do ciclismo e propor um zoneamento do uso público na E. E. Tupi onde o ciclismo seja concentrado nestas trilhas e as trilhas mais próximas do Centro de Visitantes mantenham o objetivo de uso para outras atividades, como caminhada, corrida, corrida de orientação e passeio.

No encontro de abril, o caminho percorrido foi de 3,1 km. Contudo, foi decidido coletivamente que este caminho não seria inserido no planejamento e manejo das trilhas para ciclismo naquele momento, por ser um carreador que necessitava de um manejo mais intenso, envolvendo mudanças no delineamento e trajeto que não conseguiriam ser encaixadas no cronograma de trabalho, e que não estavam em consonância com a aprovação da pesquisa pelo COTEC (Comissão Técnico-científica do Instituto Florestal), segundo a qual o manejo deveria ser feito em trilhas já existentes sem a abertura de novas trilhas.

\section{Encontro de planejamento IV - junho/2018}

Esta coleta de dados foi realizada em junho de 2018 com vinte e cinco pessoas, sendo dezenove ciclistas, dois funcionários da prefeitura de Piracicaba, uma funcionária do Instituto Florestal e três pessoas da comunidade acadêmica (dois estudantes de graduação e uma docente).

Na ocasião, foi percorrida a Trilha do Limoeiro uma segunda vez para decidir com os ciclistas pontos onde placas de sinalização na trilha seriam oportunas para direcionar o percurso. A opinião dos ciclistas nesse quesito é importante, porque diferentemente de pedestres, os ciclistas vêm em maior velocidade pela trilha e, se as placas são colocadas 
imediatamente antes dos pontos de curva, por exemplo, é possível que o ciclista perca a entrada sem tempo de fazer sua manobra. Além disso, a altura de um ciclista montado na bicicleta é diferente da média de altura dos pedestres, e todos estes pontos tinham que ser considerados para a sinalização eficaz da trilha.

Também nesta ocasião foi debatido mais uma vez se obstáculos seriam de interesse em pontos da trilha previamente apontados por um funcionário da Estação como passíveis da inserção de obstáculos sem que isso prejudicasse o uso do mesmo caminho para a manutenção da trilha e resgate.

Por fim, foram consideradas, também com os participantes, duas datas possíveis para o último encontro de planejamento da trilha, em julho. Estas datas, por meio de uma enquete online com o formulário Google Forms, foram abertas para a votação dos demais visitantes presentes na mailing list construída a partir das entrevistas em campo.

A data escolhida pela maioria foi 22 de julho de 2018, um domingo pela manhã.

\section{Encontro de planejamento $V-j u l h o / 2018$}

Em 22 de julho, apesar dos esforços em tornar a escolha das datas para os encontros mais democrática abrindo-as para votação, apenas oito sujeitos compareceram, sendo três ciclistas de Santa Bárbara do Oeste, uma cidade vizinha a Piracicaba, uma funcionária do Instituto Florestal, uma docente universitária e três estudantes de graduação envolvidos no trabalho.

Esse encontro foi o último de planejamento da trilha, em que se discutiram os conteúdos informativos das placas de sinalização, possíveis datas para os mutirões de manejo da trilha nos meses de agosto e setembro e, mais uma vez, foi consultada a inserção de obstáculos na trilha.

Como já havia sido sugerido nos encontros de fevereiro e junho, quando também foram consultados os presentes sobre o interesse em obstáculos na trilha para ciclismo, ficou decidido, finalmente, que não haveria obstáculos na trilha, pois o perfil do ciclista que utiliza a E.E. Tupi é o da modalidade cross country, que se motiva mais por caminhos a percorrer, e não por obstáculos a superar.

Encontro VI-Mutirão de manejo da trilha I-agosto/2018

Esse encontro foi realizado nos dias 18 e 19 de agosto, um final de semana, com três turnos de atividade para que os participantes pudessem escolher a sua melhor conveniência. 
No sábado, o primeiro turno de trabalho foi das $8 \mathrm{~h}$ ao meio dia e, após uma pausa para almoço coletivo, houve outro turno das $13 \mathrm{~h}$ às $16 \mathrm{~h}$. No domingo houve apenas o turno da manhã.

Compareceram dezessete indivíduos no sábado (três ciclistas, uma docente universitária, doze estudantes de graduação e um funcionário da prefeitura de Piracicaba), e sete indivíduos no domingo (um ciclista, cinco alunos de graduação e uma funcionária da prefeitura de Piracicaba).

As atividades de manejo da trilha executadas foram:

- Um canal de drenagem;

- Limpeza da trilha;

- Remoção de tronco do leito da trilha;

- Nivelamento da trilha (cobertura de buracos e processos erosivos).

Neste encontro, assim como no seguinte, os indivíduos participantes assinaram um Termo de Responsabilidade na hipótese de que algum acidente ocorresse durante o mutirão. Também utilizaram o EPI (equipamento de proteção individual) correspondente à atividade (capacete, luva, óculos e perneira).

\section{Encontro VII - Mutirão de Manejo da Trilha II - setembro/2018}

Em 15 e 16 de setembro, no mesmo formato de trabalho do mutirão do mês de agosto, sete indivíduos estiveram presentes no sábado (um ciclista, cinco alunos de graduação e um aluno de pós-graduação), e quatro no domingo (uma docente universitária e três alunos de graduação).

Foram pintadas as placas de sinalização e executados os nivelamentos de trilha (cobertura de buracos e processos erosivos) que faltavam.

No final de semana seguinte, em 22 de setembro de 2018, Dia Mundial Sem Carro, um sábado, foi aberta a Trilha do Limoeiro para uso.

\section{Avaliação do processo de gestão participativa}

Após a abertura da Trilha do Limoeiro para uso, foi elaborado um questionário de dez questões para que os participantes pudessem avaliar o processo de gestão participativa e sugerir melhoras para iniciativas futuras. 
Em cada encontro do processo houve uma lista de presença a ser preenchida com o nome e e-mail dos participantes, assim, o questionário de avaliação pode ser encaminhado junto a um certificado de participação com a carga horária de cada voluntário.

No decorrer do processo de gestão participativa, em 2018, sessenta e duas pessoas participaram, sendo trinta e sete ciclistas (59,7\%), um participante foi um visitante pedestre $(1,6 \%)$, dezenove foram pessoas vinculadas à comunidade acadêmica $(30,6 \%)$ e cinco eram funcionários públicos de órgãos ambientais gestores da unidade $(8,1 \%)$.

A maioria dos participantes (75,0\%) compareceu a apenas um dos sete encontros de planejamento e manejo da trilha. Os motivos dessa participação isolada foram questionados no formulário de avaliação do processo, sendo que $80 \%$ dos respondentes disseram não terem participado de mais encontros devido a conflitos com outros compromissos pessoais. $10 \%$ acredita não ter sido corretamente informado sobre as datas dos encontros e $10 \%$ não reportou nenhuma justificativa.

- Os participantes que estiveram em mais de um encontro disseram tê-lo feito:

- Pela vontade de ver algo comunitário sendo feito, algo pela sociedade;

- Pela oportunidade de participar de um projeto que poderia ser futuramente usufruído por ele;

- Pelo fato de se aproximar da natureza durante o processo de gestão participativa;

- Porque o uso e a conservação das áreas naturais devem ser bem planejados;

- Porque a pessoa se sentiu comprometida a fazer algo pelo bem comum;

- Porque considerou o projeto importante.

Por fim, foi questionado se os sujeitos participariam de um grupo permanente de voluntários para o necessário manejo contínuo das trilhas de ciclismo na E.E. Tupi. Devido à baixa adesão dos sujeitos durante o processo em si, já era esperado que a formação desse grupo não seria possível neste momento. Dos respondentes da avaliação, $60 \%$ disse que sim, participaria da formação do grupo voluntário (e deixaram um meio de contato), mas essa intenção de participação já foi menor que a encontrada durante as entrevistas preliminares presenciais, em 2017 , quando $66,1 \%$ dos visitantes não ciclistas e $78,5 \%$ dos ciclistas manifestaram intenção de participação na gestão da trilha. 


\section{Conclusão}

Nesta pesquisa, optou-se por propor o planejamento e o manejo de uma trilha para ciclismo como uma estratégia de aproximação da sociedade com o cuidado das áreas naturais. Ora, se aumenta a procura destas áreas para lazer e recreação, por que não aumenta o envolvimento das pessoas no seu cuidado e manutenção?

Sobre a intenção de participação e o real engajamento das pessoas em causas ambientais, o Instituto Ecosurf, fundado no ano 2000 por surfistas para realizar mutirões de limpeza e sensibilização ambiental com o objetivo de conter o avanço da poluição em praias paulistas, divulgou uma imagem em sua página de rede social em 2020 (figura 2).

Figura 2: Sobre a participação real de voluntários.

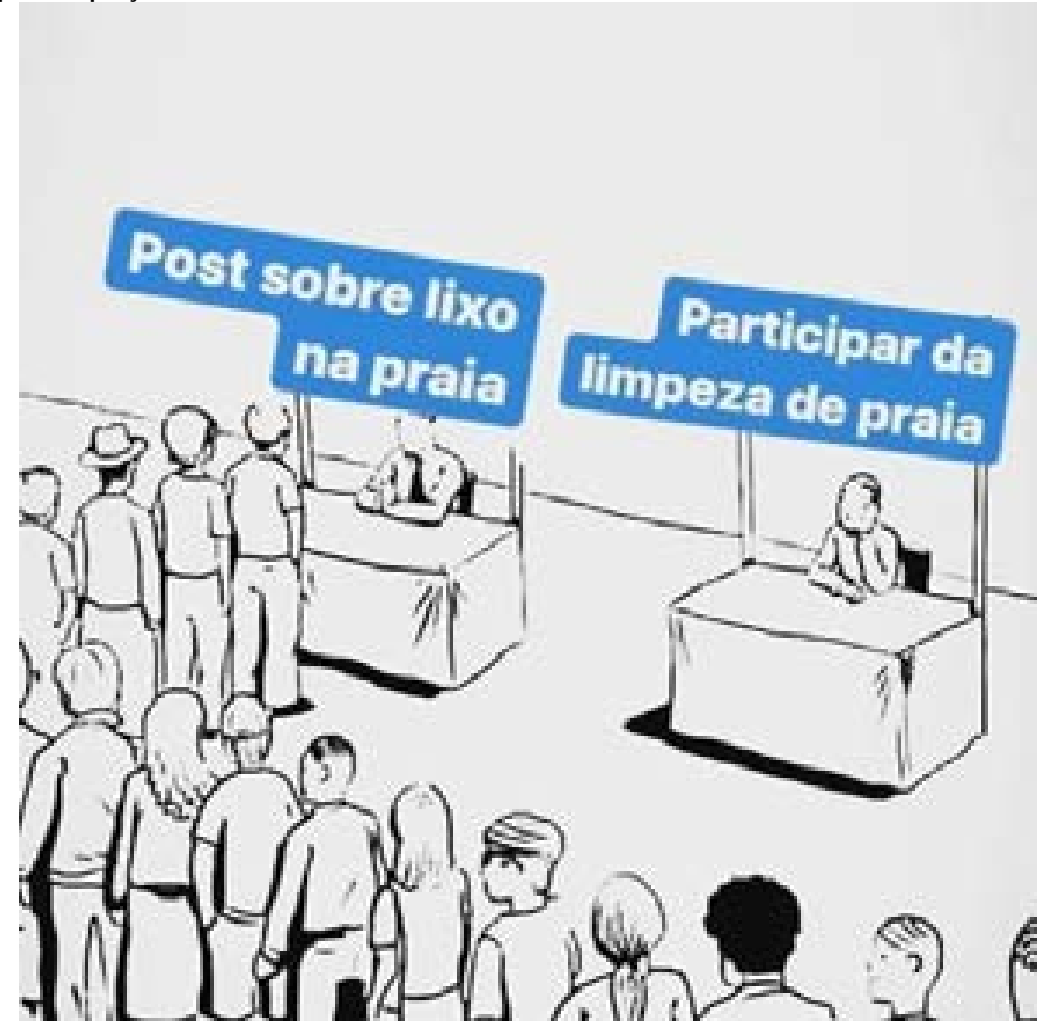

Fonte: Instituto Ecosurf (2020).

Essa imagem reflete uma problemática atual em que as pessoas têm uma facilidade grande em, através das mídias sociais, dar opiniões e colocar-se disponíveis ou interessadas em temas e eventos, quando na realidade seu engajamento com os mesmos será muito menor. Por exemplo, a divulgação do primeiro mutirão de manejo da Trilha do Limoeiro, em 
agosto de 2018, foi feita através do Facebook, em que sessenta e três pessoas responderam como interessadas ou confirmadas para o evento. Na realidade, compareceram vinte e quatro.

Écerto que há diferentes razões para a baixa adesão de voluntários, desde os conflitos com compromissos pessoais, apontados na avaliação desta pesquisa, à possibilidade de má divulgação das datas dos encontros para as atividades, também apontada no questionário de avaliação.

A experiência na Estação Experimental deTupi não obteve o êxito esperado, mas há outras, como a do próprio relato de caso que inspirou esta pesquisa (NEWSOME et al, 2016) que apontam para vantagens em construir parcerias com os visitantes das áreas naturais protegidas.

Ações de gestão participativa e continuada têm potencial para, através do envolvimento da sociedade civil, dificultar a perda de áreas protegidas públicas para a iniciativa privada, uma vez que a população que faz uso destes espaços consiga se apropriar e ressignificar a área para seu uso e cuidado.

\section{Referências}

ALERJ. Associação Legislativa do Estado do Rio de Janeiro (2019) Lei cria programa para incentivar o ciclismo de montanha. Disponível em: < http://www.alerj.rj.gov.br/Visualizar/ Noticia/45137? AspxAutoDetectCookieSupport=1>. Acesso em: 03 mar. 2020.

AJZEN, I. The Theory of Planned Behaviour. Organizational Behaviour and Human decision Processes, v.50, n.2, p.179-211, 1999.

BARTOLETTI, C.; MAGRO-LINDENKAMP, T. C. Gestão participativa de uma trilha para ciclismo de montanha: um estudo de caso. Revista Gerencia Deportiva, v. 4, p. 2-23, 2020.

CORTELLA, M.S. A falsa adesão ao isolamento social é imoral. Disponível em: <https://cbn.globoradio.globo. com/media/audio/297985/falsa-adesao-ao-isolamento-social-e-imoral.htm >. Acesso em: 13 abr 2020.

HADDAD, N. M.; BRUDVIG, L. A.; CLOBERT, J.; DAVIES, K. F.; GONZALEZ, A.; HOLT, R. D.; TOWNSHEND, J

HEYWOOD, A. Ideologias políticas: do feminismo ao multiculturalismo. São Paulo: Ática, 142p, 2010.

ICMBio - INSTITUTO CHICO MENDES DE CONSERVAÇÃO DA BIODIVERSIDADE. Parques do Brasil: visitar é proteger! Disponível em: < https:// parques_do_brasil_estrategia_implementacao_visitacao_2018_2020_ ICMBio.pdf>. Acesso em 07 dez. 2020.

INSTITUTO FLORESTAL. Práticas Esportivas na Estação Experimental de Tupi. Disponível em: < http:// iflorestal.sp.gov.br/2016/07/22/praticas-esportivas-na-estacao-experimental-de-tupi/ >. Acesso em 23 ago, 2016.

MANNING, R.E. Parks and People, 1a ed. Vermont: University of Vermont Press, 335 p, 2009. 
MATTAR, F. N. Pesquisa de Marketing: metodologia, planejamento, execução e análise. $4^{\text {a }}$ ed. São Paulo: Atlas, 2007, 336p, 2007.

MATHEUS, F.S.; RAIMUNDO, S. Public use and Ecotourism Policies in Brazilian and Canadian Protected Areas. Études caribéennes, 33-34, 2016. DOI: 10.4000/etudescaribeennes.9344

NEWSOME, D.; MOORE, S. A.; DOWLING, R. K. Natural area tourism: Ecology: Impacts and management. $2 \rrbracket$ ed. Bristol: Channel view publications. 457p, 2012.

NEWSOME, D.; STENDER, K.; ANNEAR, R.; SMITH, A. Park management response to mountain bike trail demand in South Western Australia, Journal of Outdoor Recreation and Tourism, v.15, 26-34, 2016.

OUTDOOR FOUNDATION. Outdoor Recreation Participation Report. Boulder, CO: The Outdoor Foundation, 73p, 2011.

PICKERING, C.; HILL, W.; NEWSOME, D.; LEUNG, Y. Comparing hiking, mountain biking and horse-riding impacts on vegetation and soils in Australia and the United States of America. Journal of Environmental Management, v. 91, p 551-562, 2010.

PINHEIRO,G.S.; GIANNOTTI,E.; CRESTANA,C.S.M.; PFEIFER,R.M.; SILVA,D.A.; NEGREIROS,O.C.; BARBOSA,A.F.; MARIANO,G.; GUTMANIS,D.; ROMANELLI,R.C.; SILVA. Plano de manejo da Estação Experimental de Tupi. Piracicaba, SP: Instituto Florestal, 61p, 1999.

RHIRY-CHERQUES, R.H. Saturação em pesquisa qualitativa: estimativa empírica de dimensionamento. Revista Brasileira de Pesquisa em Marketing. Disponível em: < http://www.revistapmkt.com.br/Portals/9/Edicoes/ Revista_PMKT_003_02.pdf> Acesso em 15 out. 2016.

ROSSI, S. D., PICKERING, C. M., BYRNE, J. Perceptions of stakeholder organisations: assessing the social impacts of the South East Queensland Horse Riding Trail Network. Brisbane, QLD: Griffith University. 50p, 2013.

SÃO PAULO Tupi. Disponível em: < http://iflorestal.sp.gov.br/areas-protegidas/estacoes-experimentais/tupi/ $>$. Acesso em: 29 mar 2017.

THIOLLENT, M. Metodologia da pesquisa-ação. 18a ed. São Paulo: Cortez, 136p, 2018.

WOLF, I.; WOHLFART, T.; BROWN, G.; LASA, A.; TORLAND, M. Monitoring and management of mountain biking through public participation geographic information systems. In: Proceedings of the 7th MMV. VII International Conference on Monitoring and Management of Visitors in recreational and protected areas (pp. 158160), Tallinn, Estonia, 2014. 